\title{
Screening Environmental Impact Reduction Enabled by Brass Reclamation Through Hot Forging Operations
}

\author{
Jakob JOHANSSON ${ }^{\mathrm{a}, 1}$, Anna FURBERG ${ }^{\mathrm{b}}$ and Fredrik SCHULTHEISS ${ }^{\mathrm{a}}$ \\ ${ }^{a}$ Lund University, Division of Production and Materials Engineering, Lund, Sweden \\ ${ }^{\mathrm{b}}$ Chalmers University of Technology, Division of Environmental Systems Analysis, \\ Gothenburg, Sweden
}

\begin{abstract}
The traditional method for recycling brass chips is to send the scrap back to the material manufacturer for re-melting. Alternatively, brass chips can be reclaimed through hot forging operations at the production site. As an initial screening of the environmental impact of this novel reclamation method, the impacts of this new method was compared to conventional brass production (including recycling) for a specific part. These two production routes were compared in terms of cumulative energy demand and climate change impact. The comparison between the two production routes showed that the new reclamation method reduced the cumulative energy demand with $29 \%$ and climate change impact with $30 \%$ for production of a specific part compared to conventional recycling. It is, however, important to note that the material produced using hot forging reclamation method have slightly lower mechanical properties as compared to the traditionally recycled material. Currently the novel recycling method is only tested in lab scale and therefore, further studies are needed in order to fully assess the environmental impacts of the new reclamation method compared to conventional brass production.
\end{abstract}

Keywords. Life cycle assessment (LCA), Resource efficient production, Recycling, Brass

\section{Introduction}

Brass is a common engineering material used in many applications, e.g. heating systems, water fittings, and home furnishings. During production, many brass parts require a significant amount of material removal, material which need to be recycled in some way. The traditional method for recycling metal, including brass, is through remelting at a foundry. This is an effective method of recycling the material as theoretically all available scrap can be recycled into new raw material with the same material properties [1]. However, this method of recycling comes with the drawback that the scrap material must be transported to a foundry and heated above the materials melting point, around $900{ }^{\circ} \mathrm{C}$ dependent on alloy, and processed before sending it back, potentially to the same part manufacturer. Thus, the recycling process consumes a notable amount of resources, time and energy.

As previously shown, chips from metal cutting can be reclaimed through hot forging operations for many materials [2, 3], including brass [4-6]. If done in conjuncture with

\footnotetext{
${ }^{1}$ Corresponding Author. jakob.johansson@iprod.lth.se
} 
production at the same manufacturing plant where the chips are originally created, resources savings can be envisioned. As observed by Johansson et al. [7], the hot-forging reclamation process will result in a minor decrease in mechanical properties, however, the environmental implications of this novel recycling methods have not yet been explored. Through conducting this type of simplified material reclamation, that do not include melting of materials, in house at the part producer, potential resource and environmental benefits are envisioned. By making material reclamation a part of the production system, a certain amount of brass material from conventional production (including recycling) can be avoided. Thus, the aim of this study is to compare the environmental impact of the new hot-forging reclamation method as compared with conventional brass production applying the case of producing a T-pipe fitting.

\section{Brass recycling through in-house hot forging operations}

Chips are an inevitable waste product of all machining operations, including the machining of brass. The geometry of many products commonly manufactured in brass, i.e. pipe fittings and valves, mean that a substantial amount of raw material will be turned into chips during production. In this study, a brass T-pipe fitting was applied as a case study, Figure 1. In conventional production, the part is hot forged from rod material to a blank for subsequent machining operations into a finished part. Due to the large amount of scrap material, efficient recycling is a mean to decrease the environmental impact of this type of production. As previously published, brass chips can be recycled through a compaction and hot forging operation in-house with only minor decrease in mechanical properties $[4,7]$.

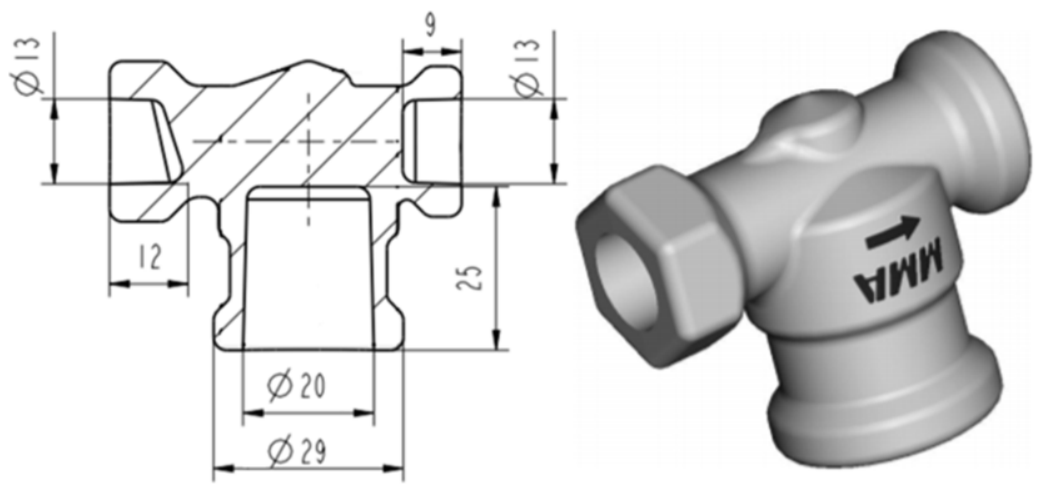

Figure 1. A T-pipe fitting in the form of a blank for subsequent machining operations.

\subsection{Hot forging brass reclamaiton process}

The newly developed recycling process is similar to conventional powdermetallurgical operations. The brass chips, taken directly from the machining process, are first milled to reduce the size of the chips using a jar mill. The next step is to reduce the amount of cutting fluid, which become mixed with the chips in the cutting operation. In brass machining operations it is common to use mineral oil as cutting fluid [8]. This oil can be used as a lubricant in the compaction process and thus, it is not necessary to completely remove it from the chips. It is, however, necessary to reduce the amount of 
oil mixed in with the chips to a suitable level for optimal material properties in the finished product [7]. The amount of oil mixed with the chips is reduced by centrifugation.

When the chips have obtained an appropriate size distribution and amount of lubricants, a green compact can be manufactured by compaction. The chips are loaded into a steel mould and heated to $400{ }^{\circ} \mathrm{C}$. The entire steel mould is heated using an induction heater and the temperature is monitored close to the brass chips. When the chips have reached the designated temperature compaction is carried out, using a compaction pressure of $800 \mathrm{MPa}$. Two rams are used to achieve dual-axis pressing and thereby, higher compaction ratio.

After compaction, the green compacts are put into a furnace and heated before being forged, in the same way as rod material. Figure 2 shows a summary of the process steps for the hot forging reclamation process and outlines how the reclamation process interconnects with the conventional manufacturing system.

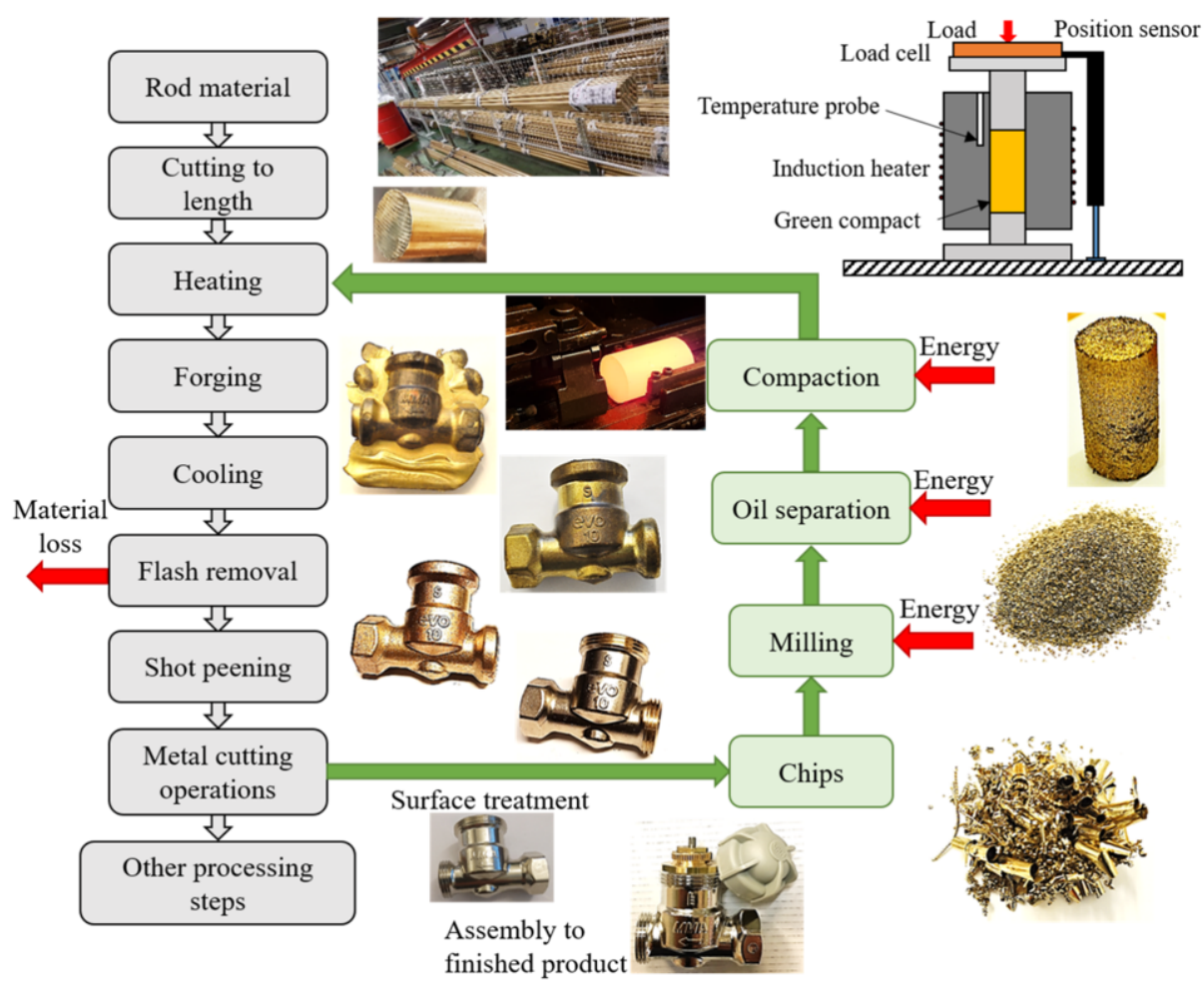

Figure 2. General process steps in the hot forging reclamation process.

\subsection{Material properties}

As is commonly the case with powder metallurgically manufactured alloys, reclaimed brass never reaches the same density as the original cast material. Instead a density of $>99 \%$ is feasible [4]. This implies that reclaimed brass will contain a distinguishable amount of contamination, dominantly in the form of porosity, Figure 3. Thus, reclaimed brass will have somewhat poorer material properties as compared to cast 
material. However, as demonstrated by Johansson et al. [7], the properties of the reclaimed material will still be good enough for many applications with a reduced maximum shear strength of $6-33 \%$, although the reduced mechanical properties can potentially lead to limitations in the application area for the method.

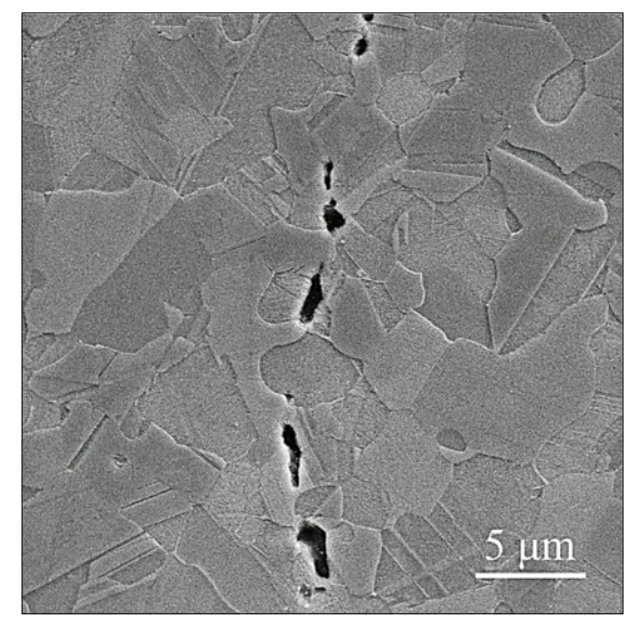

Figure 3. Microstructure of a forged part using the hot forging reclamation process. The image shows grain growth between two chips, indication partially successful bonding between the chips.

\subsection{Compared manufacturing systems}

When producing the considered part using rod material, a piece of brass rod weighing $202 \mathrm{~g}$ is needed to produce one T-pipe fitting where the finished part weighs $90 \mathrm{~g}$. The removed material consist of $24 \mathrm{~g}$ flash, which cannot be recycled via the novel method. However, the remaining $88 \mathrm{~g}$ of scrap is removed as chips via metal cutting and are thus suitable for the new hot forging material reclamation procedure. Slightly more material, $250 \mathrm{~g}$, is needed when applying the hot forging reclamation to ensure even material quality after forging compared to using rod material. Due to this fact, the $88 \mathrm{~g}$ of material removed as chips can only replace $71 \mathrm{~g}$ of rod material when applying the brass reclamation method. The excess material is removed in the deflashing of the part.

A majority of the cutting fluid has to be removed from the chips before reclamation and this oil separation is necessary in both manufacturing cases why the energy needed for this process will not be considered in the analysis. However, the $0.5 \mathrm{~g}$ oil per part that is required for the reclamation process to function properly will be included.

As previously stated, the chips have to be ground before compaction. The milling process requires some energy, but relatively large batches of material can be milled simultaneously, resulting in an energy requirement of $0.02 \mathrm{kWh}$ per part. Energy is also needed to compact the chips into green compacts, $0.036 \mathrm{kWh}$ per part.

The energy requirements for the heating is difficult to quantify since it depends on if the mould is heated or not, i.e. the heating energy is not the same on the first compact produced and the subsequent details. In theory, the energy required to heat $250 \mathrm{~g}$ of chips is approximately $0.01 \mathrm{kWh}$, according to: 


$$
Q=\Delta T \cdot c_{p} \cdot m
$$

where $\mathrm{Q}$ is amount of heat applied, $\Delta \mathrm{T}$ is temperature rise, $\mathrm{m}$ is mass of the heated object and $c_{p}$ is the materials specific heat capacity. $c_{p}$ was measured by Laser Flash Analysis at room temperature. Considerably more energy is required in practice due to heat loss, losses in energy conversion etc. why the electricity required for heating was estimated to $0.03 \mathrm{kWh}$ per part.

\section{Screening life cycle assessment}

Today, the traditional method for recycling brass is sending the scrap back to the foundry for re-melting. As described in the previous section, a new method for reclamation of brass chips has been developed which in part could substitute re-melting as a recycling method. However, to evaluate the merits of the new recycling method it is important to evaluate the whole material lifecycle in comparison to traditional methods. As the difference between the two compared recycling methods starts after the scrap has been produced by the manufacturer, this will be the starting point of the life cycle assessment.

Life cycle assessment (LCA) is commonly applied in order to assess environmental impacts of products (and also services) [9]. In an LCA, impacts are assessed over the product's life cycle, including raw material extraction, production, use and waste management (called a cradle-to-grave LCA) or including a certain part of the life cycle, such as from raw material extraction to production (called a cradle-to-gate LCA). In this study, a screening cradle-to-gate LCA was conducted with the purpose to compare environmental impacts of producing one brass T-pipe fitting via the new production route, including hot forging reclamation, with conventional production including recycling.

The compared systems are illustrated in Figure 4 and described in more detail in section 1.1 Hot forging brass reclamaiton process. An important part of LCA is the definition of a functional unit, which provides a quantitative measure to which all impacts are related. In this study, the functional unit was set to one $(90 \mathrm{~g})$ brass T-pipe fitting. The cumulative energy demand, which is the primary energy consumption quantified in $\mathrm{MJ}$ equivalents, and climate change impact, which is the contribution to global warming quantified in $\mathrm{kg} \mathrm{CO}_{2}$ equivalents, was calculated for the two compared systems in relation to this functional unit. The cumulative energy demand [10] and ReCiPe (version 1.1, hierarchist scenario, 2016) [11] impact assessment methods was applied in order to quantify these impacts based on knowledge about the energy, inputs and outputs required for the production of one brass T-pipe fitting via the two production systems. The provided results from this screening LCA are preliminary since the new production route for brass is still on a laboratory scale. 
Production with hot forging brass reclamation

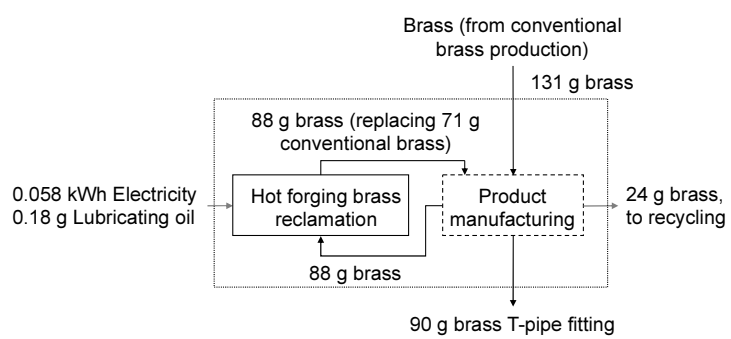

\section{Conventional production}

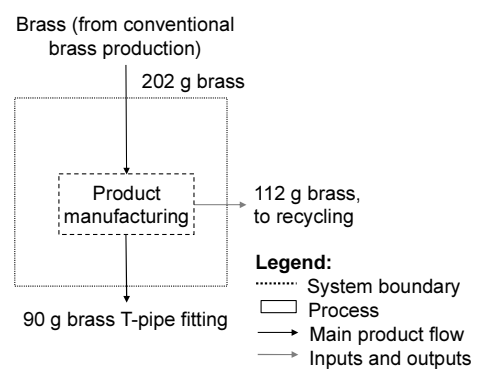

Figure 4. Systems compared. Note that the product manufacturing process, marked with dashed lines, was not included in the calculations since this process is similar for the two compared systems.

In order to be able to assess the impacts of the brass T-pipe fitting, a lot of data on the associated energy, inputs and outputs are required. Data for conventional brass production (including recycling) as well as for the electricity and lubricating oil needed in hot forging brass reclamation, was applied from the Ecoinvent database version 3.5 [12] and selected to represent the global market including transport (and transmission losses in the case of electricity production). The OpenLCA software version 1.8 [13] was applied for the calculations. Recycled brass, not available for hot forging brass reclamation, Figure 4, was "cut off" and not included anymore in the assessment [14].

The preliminary results for cumulative energy demand and climate change of the two compared systems for the production of one T-brass pipe fitting are presented in Figure 5 and show that the impacts of the new production route, including hot forging brass reclamation, is lower compared to conventional brass production. The impacts of producing one T-pipe fitting with the new production route is reduced with $29 \%$ for the cumulative energy demand and $30 \%$ for climate change impact compared to conventional production.

a)

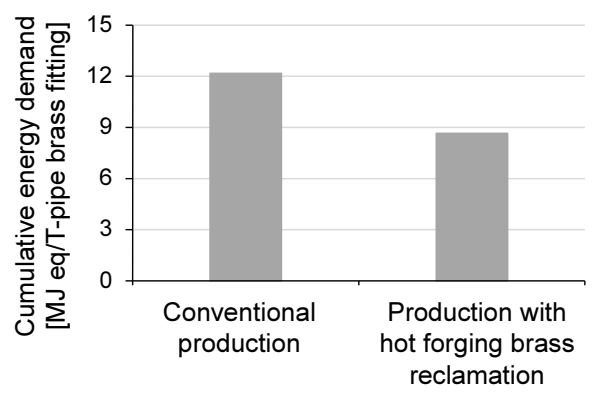

b)

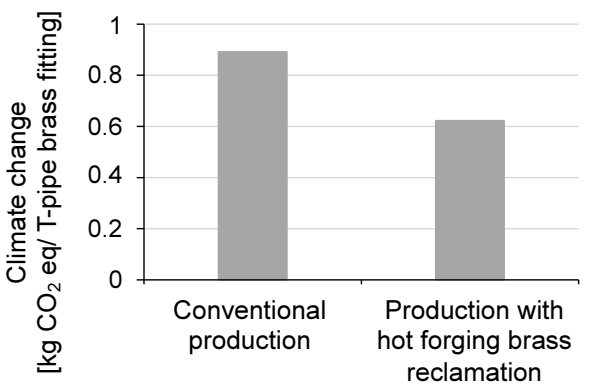

Figure 5. Environmental impact, including a) cumulative energy demand [MJ eq.] and b) climate change [kg $\mathrm{CO}_{2}$ eq.] for conventional production and production with hot forging brass reclamation of one T-pipe fitting.

\section{Discussion}

Detailing the performance of a manufacturing system not yet existing in full scale is not trivial. Throughout this work, the authors have attempted to make a fair comparison 
between the two recycling cases based on independent data and scientific practices. Thus, the authors believe the preliminary results to be a valid and fair comparison between the two in this screening study.

The comparison made in this paper is based on the assumption that no significant degradation of the recycled material occurs over time, an assumption that needs to be experimentally verified. However, a comprehensive experimental investigation in this regard is still lacking, the result of which may influence the conclusions reached in this initial comparison.

Brass reclamation through hot forging is still on a laboratory scale, although with good results as outlined in this paper. Given adequate time, upscaling and optimization of the proposed method would, arguably, imply an improved reclamation process and thus reduced energy requirements for the process and potentially other benefits, such as improved mechanical properties. Since there is, currently, no existing production system to perform measurements on, there is some uncertainty associated with the numbers presented in this work; unforeseen problems may arise when scaling up the method for production and the production cost is not yet fully analyzed.

Although an initial investment in equipment is required for the new method, the preliminary results showing reduced cumulative energy demand and climate change impact, roughly $30 \%$ for each, an industrial implementation of the new brass hot forging reclamation method has the potential to be an adequate supplement to modern part production in brass, given that suitable part performance can be achieved. The method is proven to work in specific situations. Thus, the next step for this research is to attempt a full-scale industrial implementation of the method.

\section{Conclusions}

A screening cradle-to-gate LCA has been conducted in order to compare the environmental impact of a newly developed brass hot forging material reclamation method as compared to conventional brass production including recycling for the case of a T-pipe fitting. Assuming otherwise the same manufacturing process for both cases a screening cradle-to-gate LCA was conducted.

The preliminary results from the screening LCA show that the application of the hot forging brass reclamation process in the production of one T-pipe fitting reduce the cumulative energy demand with $29 \%$ and climate change impacts with $30 \%$ compared to conventional brass production. These results need to be confirmed by further studies also considering potential material quality differences and full scale application of the hot forging brass reclamation process.

\section{Acknowledgement}

The research presented in this paper is part of the EvoChip research project funded by MISTRA, The Swedish Foundation for Strategic Environmental Research. It is also a part of the Sustainable Production Initiative cooperation between Lund University and Chalmers University of Technology. The author would like to acknowledge the valuable contributions made by AB Markaryds Metallarmatur. 


\section{References}

[1] R.S. Kaplan H. Ness, Recycling of Metals (Reprinted from Encyclopedia of Materials Science and Engineering, 1986), Conservation \& Recycling, Vol. 10, 1987, pp. 1-13.

[2] J.R. Duflou, A.E. Tekkaya, M. Haase, T. Welo, K. Vanmeensel, K. Kellens, W. Dewulf D. Paraskevas, Environmental assessment of solid state recycling routes for aluminium alloys: Can solid state processes significantly reduce the environmental impact of aluminium recycling?, CIRP Annals, Vol. 64, 2015, pp. 37-40.

[3] S.S. Khamis, M.A. Lajis R.A.O. Albert, A Sustainable Direct Recycling of Aluminum Chip (AA6061) in Hot Press Forging Employing Response Surface Methodology, in 12th Global Conference on Sustainable Manufacturing - Emerging Potentials. 2015. p. 477-481.

[4] J. Johansson, L. Ivarsson, J.E. Stahl, V. Bushlya F. Schultheiss, Hot forging operations of brass chips for material reclamation after machining operations, Procedia Manufacturing, Vol. 11, 2017, pp. 584-592.

[5] N. Manukyan, L. Khachatryan, G. Petrosyan, É. Bodzhikyan, K.L. Petrosyan, A. Gevorkyan S. Agbalyan, Production technology and properties of extruded materials from brass swarf, Soviet Powder Metallurgy, Vol. 22, 1983, pp. 474-478.

[6] T. Nakagawa, T. Tanaka T. Amano, Powder Forging of High-Strength Brass and Its Application to Automobile Parts, Journal of Mechanical Working Technology, Vol. 2, 1978, pp. 179-195.

[7] J. Johansson, O. Gutnichenko, J.E. Ståhl, V. Bushlya F. Schultheiss, Determining process parameters for successful material reclamation of lead-free brass chips using hot forging operations: Lubrication, Procedia CIRP, Vol. 80, 2019, pp. 108-113.

[8] M.A. El Baradie, Cutting fluids: Part I. Characterisation, Journal of Materials Processing Technology, Vol. 56, 1996, pp. 786-797.

[9] A. Tillman H. Baumann, The Hitchhikers guide to LCA. (2004), Lund, Sweden: Studentlitteratur AB.

[10] R. Frischknecht, F. Wyss, S.B. Knopfel, T. Lutzkendorf M. Balouktsi, Cumulative energy demand in LCA: the energy harvested approach, International Journal of Life Cycle Assessment, Vol. 20, 2015, pp. 957-969.

[11] M.A.J. Huijbregts, Z.J.N. Steinmann, P.M.F. Elshout, G. Stam, F. Verones, M. Vieira, M. Zijp, A. Hollander R. van Zelm, ReCiPe2016: a harmonised life cycle impact assessment method at midpoint and endpoint level, International Journal of Life Cycle Assessment, Vol. 22, 2017, pp. 138-147.

[12] Ecoinvent. Ecoinvent database version 3.5. 2018.

[13] GreenDelta. Open LCA software version 1.8. 2019.

[14] T. Ekvall A.M. Tillman, Open-Loop Recycling: Criteria for Allocation Procedures, International Journal of Life Cycle Assessment, Vol. 2, 1997, pp. 155-162. 